\title{
Optimal Promotional Effort Policy in Innovation Diffusion Model Incorporating Dynamic Market Size in Segment Specific Market
}

\author{
Sunita Mehta \\ Department of Mathematics, \\ Amity Institute of Applied Sciences, \\ Amity University, Noida, U.P., India. \\ E-mail: sunitasharmav78@gmail.com \\ Kuldeep Chaudhary \\ Department of Mathematics, \\ Amity Institute of Applied Sciences, \\ Amity University, Noida, U.P., India. \\ Corresponding author: chaudharyiitr33@gmail.com \\ Vijay Kumar \\ Department of Mathematics, \\ Amity Institute of Applied Sciences, \\ Amity University, Noida, U.P., India. \\ E-mail: vijay_parashar@yahoo.com
}

(Received December 16, 2019; Accepted March 15, 2020)

\begin{abstract}
Due the increasing globalization of market and diverse consumer groups, market segmentation becomes an ever more important concept in current market scenario. After market segmentation, firms use the available promotional strategies to target market. In this paper, we present a model of determining the optimal dynamic promotional policies for a product in segmented market incorporating dynamic market size, where sales is assumed to be evolved through mass and differentiated promotion. Mass promotional effort is allowed in whole market with a fixed spectrum for each segment while differentiated promotion is targeted to each segment independently. The optimal promotional effort policy for each segment is obtained by applying maximum principle. Numerical illustrations are provided to show the effectiveness of the proposed method and solution procedure by discretizing the optimal control model. Furthermore, sensitivity analysis of the discount rate parameter is carried out and presented.
\end{abstract}

Keywords- Maximum principle, Dynamic potential market, Differentiated promotion, Mass promotion.

\section{Introduction}

Industrialization plays a very significant role in bringing technological progress in the society. This leads to abundance of similar goods and services. In order to compete for a substantial market, companies have to device ways to popularize their products. Policy makers have to design policies to get across the consumers and aware them regarding the quality and innovative features of the products. Companies invest heavily on promotional activities to boost the sale of the product and design the promotional activities to capture the market share. Generally, designing promotional strategies may broadly be divided into two phases. In the first phase, the target market is identified where the product can be appropriately marketed. In the second phase, strategies for promotion are designed in accordance with the desired market. It is well known that the market may not be homogeneous, therefore it is very essential to partition the consumers into various segments as per their requirements. Consumers with similar needs and preferences belong 
International Journal of Mathematical, Engineering and Management Sciences

Vol. 5, No. 4, 682-696, 2020

https://doi.org/10.33889/IJMEMS.2020.5.4.055

to the same segment and marketing strategies are designed accordingly. These potential consumers are essentially classified on the basis of their mind-set, demographic and geographic features. Effective creation of customized policies for various segments boosts the sales of the product and consequently, it gives the firm an edge over its competitors.

In the second phase, the firm finalizes the strategies for enhancing the sales of its product. The promotional efforts may be categorized into either mass promotional or segment specific promotional efforts. When the product is advertised using a common approach amongst the entire population, it is called as mass promotional strategy. On the other hand, if various approaches are designed according to the needs and behaviour of the consumers in the partitioned segments, the strategies are termed as differentiated promotional strategies. Researchers (Little and Lodish, 1969; Seidmann et al., 1987; Grosset and Viscolani, 2005; Górajski and Machowska, 2017) have proposed advertising models to study the behaviour of segmented market and applied optimal control theoretic approach to analysed the behaviour of consumers in the segmented market. The model designed by Little and Lodish (1969) considered certain media advertising options and prepared a schedule in order to achieve maximum response of the market. Seidmann et al. (1987) developed a diffusion model of sales-advertising strategy in which the adopters were segmented with regard to the level of income, geographic location and family sizes. The model considered was shown to be well posed and was studied to establish the optimal policies for advertising. Buratto et al. (2006) in their model have analysed the various advertising techniques in a partitioned market associated with a newly introduced product. Grosset and Viscolani (2005) suggested formulation of an optimal strategy for advertising a product, introduced for the first time in a market which is sub divided into groups on the basis of age. The model proposed replaced the linear model given by Nerlove and Arrow (1962) which aimed at deriving the optimal advertising and pricing policies of a firm based on the concept of goodwill. In the past, researchers have dealt with optimal control models analysing the policies related to advertising and price determination, adopted for newly introduced products in the market (Thompson and Teng, 1984; Chutani and Sethi, 2012; Stummer et al., 2015; Pan and Li, 2016; De Giovanni, 2019).

The simplest diffusion model in marketing was given by Bass (1969). The pioneering model given by Bass (1969), has since then been used extensively in the field of diffusion theory (Kapur et al., 2020). Since this model did not consider the effect of variables related to marketing, researchers have modified the model to analyse the influence of price on diffusion of a new product in the market (Robinson and Lakhani, 1975; Horsky and Simmon, 1983; Kalish, 1983; Kalish, 1985; Kamakura and Balasubramanium, 1988; Sethi and Bass, 2003). These models analyse the effect of pricing policies on diffusion of products. Researchers (Horsky and Simmon, 1983; Simon and Sebastian, 1987; Dockner and Jorgensen, 1988) have also considered models which analyse the impact of advertising policies on product diffusion. Horsky and Simmon, (1983) gave a model which modified the Bass model incorporating the effects of advertising. Thompson and Teng (1996) applied the concept of production learning curve which analysing the pricing and advertising policies in an oligopolistic market. Bass et al. (1994) gave the Generalized Bass model, which included both price and advertising strategies.

Jha et al. (2009) considered diffusion models for products that are new to the market and formulated the optimal strategies for effectively publicizing the product in a partitioned market. They further analysed the sales of a product in a segmented market under the effect of two different ways of advertising. In the first situation, the case considered that the company uses 
various independent advertising policies in different market segments. The second situation considered to have a common mode of advertising in the various segments. Huang et al. (2012) and Helmes et al. (2013) formulate and analyse optimal control models in order to decide various policies for advertising and pricing of products. Recently, Kumar et al. (2019) developed a model for optimal price and warranty policies of a newly launch product using optimal control theory and genetic algorithm solution approach is employed to explore the optimum values of price and warranty for every period of the product's life cycle. Mesak et al. (2020) proposed a model for qualitative characterization of optimal pricing and advertising policies together with the optimal ratio of the advertising elasticity of demand to its price elasticity over time. Chang et al. (2020) proposed an optimal customer relationship marketing policy in a duopolistic market, where each firm's market share depends on the CRM decisions of its own and of its competitors.

Most of the models studied so far have been taking the number of potential adopters to be constant over the time period under consideration. However, in general it is not appropriate to make such an assumption. Technological advancements, improved product quality and increased demands may result in the increase in the number of potential adopters. The accessibility of the infrastructure and other requirements pertaining to the use of innovation, also results in a varied number of potential adopters. This paper proposes a control model by assuming that the sales of a product can be enhanced by promoting the product at mass as well as differentiated levels. The optimal promotional policies are determined that maximize the total profit subject to budget constraints. Further, we have considered dynamic potential adopter population for designing optimal control policies adopted for effective advertising. The ceiling on the adopter population to be a function of time has also been considered to augment the applicability of the model. The maximum principle is used to generate the promotional effort policies. The paper aims to design optimal promotional effort for durables, with a likelihood of repeat purchasers arising due to mass and differentiated policies existing in a partitioned market.

The rest of this paper is organized as follows: In Section 2 of this paper, notations are provided for the model. Section 3 describes the model development of proposed model incorporating dynamic market. The solution approach by using Pontryagin's Maximum principle with subclass of general formulation is shown in section 4. Section 5 gives the numerical illustration for the discretized version of the problem. Finally, the conclusion limitation of the proposed model has been discussed in Section 6 .

\section{Model Notations}

To define the model, the following notations are adopted throughout this paper:

$M \quad$ : the total number of market segments and a discrete variable.

$\overline{\mathrm{Y}}_{\mathrm{I}} \quad:$ the total number of potential customers of the product in $i^{\text {th }}$ segment.

$y_{i}(t) \quad:$ the number of adopters by time $t$ for the $i^{\text {th }}$ segment at time $t$.

$u_{i}(t) \quad:$ the differentiated promotional effort rate for $i^{\text {th }}$ segment at time $t$.

$u(t) \quad:$ the mass market promotional effort rate at time $t$.

$h_{i}(t) \quad:$ the adoption rate per additional adoption for the $i^{t h}$ segment at time $t$.

$\alpha_{i} \quad:$ the segment spectrum of mass promotion.

$a_{i} \quad:$ the coefficients of external influence in $i^{\text {th }}$ segment.

$b_{i} \quad:$ the coefficients of internal influence in $i^{\text {th }}$ segment.

$\gamma \quad:$ the discount rate.

$s_{i} \quad:$ the sales price per unit for $i^{\text {th }}$ segment.

$\phi_{i}\left(u_{i}(t)\right) \quad:$ the differentiated market promotional effort cost. 
International Journal of Mathematical, Engineering and Management Sciences

Vol. 5, No. 4, 682-696, 2020

https://doi.org/10.33889/IJMEMS.2020.5.4.055

$\psi(u(t)) \quad$ : the mass market promotional effort cost.

$c_{i} \quad:$ the production cost for $i^{\text {th }}$ segment.

\section{Model Development}

In this section, we consider a monopolistic firm, which produces a single product in market with $\mathrm{M}$ market segments. The firm simultaneously uses mass market promotion and differentiated market promotion to capture the potential market in each segment respectively. Mass market promotion reaches each segment with relative segment-effectiveness. The proportionality is called segment specific spectrum. If the demand for a product increases with time, the potential market will increase with time and then $\bar{Y}_{l}(t)$ describes the growth in potential adopter population with respect to time. Under the influence of mass market and differentiated market promotion in dynamic potential market, evolution of sales rate can be described by the following differential equation:

$$
\frac{d y_{i}(t)}{d t}=h_{i}(t)\left(u_{i}(t)+\alpha_{i} u(t)\right)\left(\bar{Y}_{i}(t)-y_{i}(t)\right), i=1,2, \ldots, M
$$

with the initial condition $y_{i}(0)=y_{i 0}, \alpha_{i}>0 \& \sum_{i=1}^{M} \alpha_{i}=1$. The adoption rate $h_{i}(t)$ can be represented either as a function of time or as a function of the number of previous adopters. Since, the latter approach is used most widely in literature as in (Jha et al., 2009), it is the one applied here. Now, Eq. (1) becomes:

$$
\frac{d y_{i}(t)}{d t}=\left(a_{i}+b_{i} \frac{y_{i}(t)}{\bar{Y}_{i}(t)}\right)\left(u_{i}(t)+\alpha_{i} u(t)\right)\left(\bar{Y}_{i}(t)-y_{i}(t)\right), i=1,2, \ldots, M
$$

Profit for the firm now is valued more highly than profit later. In order to maximize the present value of the profit in a planning horizon using optimal mass and differentiated promotional effort rates for the firm in segmented market, then profit function can be represented as

$$
\operatorname{Max} J=\int_{0}^{T} e^{-\gamma t}\left(\sum_{i=1}^{M}\left[\left(s_{i}-c_{i}\left(y_{i}(t)\right)\right) \dot{y}_{i}(t)-\phi_{i}(u(t))\right]-\psi(u(t))\right) d t
$$

where, term $e^{-\gamma t}$ indicates profit in present value. We assume that the differentiated market promotional effort cost $\left(\phi_{i}\left(u_{i}(t)\right)\right)$ and mass market promotional effort $(\psi(u(t)))$ are twice continuous differentiable of $u_{i} \geq 0$ and $u \geq 0$ respectively. The production cost $c_{i}\left(y_{i}(t)\right)$ is cost for $i^{\text {th }}$ segment, that is continuous and differentiable with assumption $c_{i} y()<$.0 and $s_{i}-$ $c_{i}\left(y_{i}(t)\right)>0$.

The differentiated and mass promotion efforts are competing for limited budget expenditure during promotion strategy of the product. Therefore, firm monitors all the promotion strategies and allocates the budget among these segments. Therefore, the budget constraint for differentiated and mass promotional expenditures is represented by the following: 


$$
\int_{0}^{T}\left(\sum_{i=1}^{M} \phi_{i}\left(u_{i}(t)\right)+\psi(u(t))\right) d t \leq B_{0}
$$

where, $B_{0}$ denotes the fixed budget expenditure for all segments over planning horizon $[0, T]$. From expression (4) we see that this constraint relates to the total promotional budget expenditure that is allocated among all the segments of market. Combining the objective function Eq. (3), state Eq. (2) and constraint Eq. (4), the optimization problem can be expressed as an optimal control problem:

$$
\left.\begin{array}{l}
\operatorname{Max} J=\int_{0}^{T} e^{-\gamma t}\left(\sum_{i=1}^{M}\left[\left(s_{i}-c_{i}\left(y_{i}(t)\right)\right) \dot{y}_{i}(t)-\phi_{i}(u(t))\right]-\psi(u(t))\right) d t \\
\frac{d y_{i}(t)}{d t}=\left(a_{i}+b_{i} \frac{y_{i}(t)}{\bar{Y}_{i}(t)}\right)\left(u_{i}(t)+\alpha_{i} u(t)\right)\left(\bar{Y}_{i}(t)-y_{i}(t)\right), y_{i}(0)=y_{i 0}, \forall i=1,2, \ldots, M \\
\int_{0}^{T}\left(\sum_{i=1}^{M} \phi_{i}\left(u_{i}(t)\right)+\psi(u(t))\right) d t \leq B_{0}
\end{array}\right\}
$$

In the above formulated optimal control problem, the control variables are promotional effort rates $\left(u_{i}(t), u(t)\right)$ and state variables are the number of adopters $\left(y_{i}(t)\right)$ for all the segments.

\section{The Optimal Dynamic Promotional Strategy}

To derive the optimal promotional effort strategy, we should solve the control theory problem (5). Here, we define a new state variable $B(t)=B_{0}-\int_{0}^{T}\left(\sum_{i=1}^{M} \phi_{i}\left(u_{i}(t)\right)+\psi(u(t))\right) d t$ with $B(0)=B_{0}$ and $B(T) \geq 0$. With state variable, the above optimal control problem described in Eq. (5) can be presented as follows:

$$
\left.\begin{array}{l}
\operatorname{Max} J=\int_{0}^{T} e^{-\gamma t}\left(\sum_{i=1}^{M}\left[\left(s_{i}-c_{i}\left(y_{i}(t)\right)\right) \dot{y}_{i}(t)-\phi_{i}(u(t))\right]-\psi(u(t))\right) d t \\
\frac{d y_{i}(t)}{d t}=\left(a_{i}+b_{i} \frac{y_{i}(t)}{\bar{Y}_{i}(t)}\right)\left(u_{i}(t)+\alpha_{i} u(t)\right)\left(\bar{Y}_{i}(t)-y_{i}(t)\right), y_{i}(0)=y_{i 0}, \forall i=1,2, \ldots, M \\
\dot{B}(t)=-\left(\sum_{i=1}^{M} \phi_{i}\left(u_{i}(t)\right)+\psi(u(t))\right), B(0)=B_{0}, B(T) \geq 0
\end{array}\right\}
$$

In order to obtain the dynamic promotional effort policies, we use Pontryagin's Maximum Principle (Seierstad and Sydsaeter, 1987; Kumar et al., 2014; Kumar and Sahni, 2016; Kumar et al., 2017; Kumar et al., 2019) to solve the optimal control problem expressed in Eq. (6). The Hamiltonian function is formulated as

$$
H=\sum_{i=1}^{M}\left[\left(s_{i}-c_{i}\left(y_{i}(t)\right)+\lambda_{i}(t)\right) \dot{y}_{i}(t)-\phi_{i}(u(t))\right]-\psi(u(t))-\mu(t)\left(\sum_{i=1}^{M} \phi_{i}\left(u_{i}(t)\right)+\psi(u(t))\right)
$$


The Hamiltonian is composed of two parts and can be interpreted as a surrogate profit rate to be maximized at each instant of time $t$. It is shown from Eq. (7) that Hamiltonian represents the overall profit with both immediate and future effects taken into account. The Maximum principle states that necessary conditions for controls $u_{i}^{*}(t)$ and $u^{*}(t)$ with the corresponding state trajectory $y_{i}^{*}(t)$ to be optimal controls are the existence of continuous and piecewise continuously differentiable functions $\lambda_{i}(t)$ and $\mu(t)$ for all $t \in[0, T]$ such that the following conditions as considered in (Seierstad and Sydsaeter, 1987; Sethi and Thompson, 2000), hold:

$$
\begin{aligned}
& H^{*}\left(t, y_{i}^{*}, u_{i}^{*}, u^{*}, \lambda, \mu\right)=H\left(t, y_{i}^{*}, u_{i}, u, \lambda, \mu\right) \\
& \frac{\partial H^{*}}{\partial u_{i}}=0 \\
& \partial H^{*} / \partial u=0 \\
& \frac{d \lambda_{i}}{d t}=\gamma \lambda_{i}(t)-\frac{\partial H^{*}}{\partial y_{i}(t)}, \lambda_{i}(T)=0 \\
& \frac{d \mu}{d t}=\gamma \mu(t)-\frac{\partial H^{*}}{\partial B(t)}, \mu(T) \geq 0 \\
& B(T)+B_{0} \geq 0, \mu(T)\left(B(T)+B_{0}\right)=0
\end{aligned}
$$

The expressions $\mu(T) \geq 0, B(T)+B_{0} \geq 0, \mu(T)\left(B(T)+B_{0}\right)=0$ are known as transversality conditions for $B(t)$. The Hamiltonian function is independent to $B(t)$ and then we have $\dot{\mu}=\gamma \mu-$ $\frac{\partial H}{\partial B} \Rightarrow \mu(t)=\mu_{T} e^{\gamma(t-T)}$. Where, $\lambda_{i}(t)$ and $\mu(t)$ are known as ad-joint variables and define marginal valuation of state variables $y_{i}(t)$ and $B(t)$ at time $t$ respectively. Here, $\lambda_{i}(t)$ corresponds to the change in future profit as making a small change in $y_{i}(t)$ at time $t$ and $\mu(t)$ can be interpreted as the future profit of promotional effort per unit promotion effort expenditure at time $t$.

The Hamiltonian $H$ is strictly concave in $u_{i}(t)$ and $u(t)$ for each segment. By using the Mangasarian Sufficiency Theorem given in (Seierstad and Sydsaeter, 1987; Sethi and Thompson, 2000), there exist unique values of promotional effort controls $u_{i}^{*}(t)$ and $u^{*}(t)$ for each segment respectively from Eq. (9) and Eq. (10) as follows:

$$
u_{i}^{*}(t)=\phi_{i}^{-1}\left(\frac{\left(s_{i}-c_{i}\left(y_{i}(t)\right)+\lambda_{i}(t)\right) \frac{\partial \dot{y}_{i}}{\partial u_{i}}-\frac{\partial c_{i}}{\partial y_{i}} \frac{\partial y_{i}}{\partial u_{i}} \dot{y}_{i}}{1+\mu_{T} e^{\gamma(t-T)}}\right), i=1,2, \ldots, M
$$


$u(t)=\psi^{-1}\left(\frac{\sum_{i=1}^{M}\left(\left(s_{i}-c_{i}\left(y_{i}(t)\right)+\lambda_{i}(t)\right) \frac{\partial \dot{y}_{i}}{\partial u_{i}}\right)-\frac{\partial c_{i}}{\partial y_{i}} \frac{\partial y_{i}}{\partial u_{i}} \dot{y}_{i}}{1+\mu_{T} e^{\gamma(t-T)}}\right), i=1,2, \ldots, M$

where, $\varphi_{i}^{-1}$ and $\psi^{-1}$ are inverse functions of $\varphi_{i}$ and $\psi$ respectively. If we assume production cost is constant i.e. $c_{i}\left(y_{i}(t)\right)=c_{i}$, then optimal promotional effort policies for each segment is given by

$$
\begin{aligned}
& u_{i}^{*}(t)=\phi_{i}^{-1}\left(\frac{\left(s_{i}-c_{i}+\lambda_{i}(t)\right)\left(a_{i}+b_{i} \frac{y_{i}(t)}{\bar{Y}_{i}}\right)\left(\bar{Y}_{i}-y_{i}(t)\right)}{1+\mu_{T} e^{\gamma(t-T)}}\right), i=1,2, \ldots, M \\
& u(t)=\psi^{-1}\left(\frac{\sum_{i=1}^{M}\left(\left(s_{i}-c_{i}+\lambda_{i}(t)\right) \alpha_{i}\left(a_{i}+b_{i} \frac{y_{i}(t)}{\bar{Y}_{i}}\right)\left(\bar{Y}_{i}-y_{i}(t)\right)\right)}{1+\mu_{T} e^{\gamma(t-T)}}\right), i=1,2, \ldots, M
\end{aligned}
$$

From expressions Eq. (16) and Eq. (17), we find that the optimal promotional effort policy shows that when market is almost saturated, then the differentiated market promotional effort rate and mass promotional effort rate respectively will decrease over time. With this interpretation, it is easy to see that why there is no need of any type of promotional effort rate in the market in case of saturation. For ad-joint variable $\lambda_{i}(t)$, we have adjoint equation as

$$
\frac{d \lambda_{i}(t)}{d t}=\gamma \lambda_{i}(t)-\left(\left(s_{i}-c_{i}+\lambda_{i}(t)\right)\left(\frac{\partial \dot{y}_{i}}{\partial y_{i}}\right)\right)
$$

with transversality condition $\lambda_{i}(T)=0$. Solving Eq. (18), we get

$$
\lambda_{i}(t)=e^{-\gamma t} \int_{t}^{T} e^{-\gamma s}\left(\left(s_{i}-c_{i}+\lambda_{i}(t)\right)\left(\frac{\partial \dot{y}_{i}}{\partial y_{i}}\right)\right) d t
$$

The above expression Eq. (19) correspond to the value of future profit of having one more unit of sale or marginal value per unit of sale at time $t$. 
International Journal of Mathematical, Engineering and Management Sciences

Vol. 5, No. 4, 682-696, 2020

https://doi.org/10.33889/IJMEMS.2020.5.4.055

\subsection{Subclass of the General Formulation}

In above section, we discussed general formulation of proposed model. While the general proposed model formulation is useful to gain insight into the factors affecting the optimal promotional effort and sales, we can obtain better result for specific cases. Here, we consider the where dynamic potential market size change over time due to repeat purchase and dynamic potential adopter population. Promotional efforts towards differentiated market and mass market are costly. Let us assume that differentiated market promotional effort and mass market promotional effort costs take the following quadratic forms $\phi_{i}\left(u_{i}(t)\right)=\frac{\kappa_{i}}{2} u_{i}^{2}(t)$ and $\varphi(u(t))=$ $\frac{\kappa}{2} u^{2}(t)$ where $\kappa_{i}>0$ and $\kappa>0$ are positive constants and represent the magnitude of promotional effort rate per unit time towards $i^{\text {th }}$ segment and towards mass market respectively. This assumption is common in literature as in (Teng and Thompson, 1983), where promotion cost is quadratic.

\subsubsection{The Optimal Control Model Incorporating Dynamic Market Size}

In this section, the evolution of sales dynamics in segmented market with potential dynamic market is discussed. It is an important point to note that the market size in each segment changes over time due to increase in population, enhancement in purchasing power etc. Therefore, we assume that the size of potential market population changes with time. Then, growth rate of potential adopters is defined by the following differential equation as

$$
\frac{d \bar{Y}_{i}(t)}{d t}=g_{i} \bar{Y}_{i}(t), \bar{Y}_{i}(0)=\bar{Y}_{i 0}
$$

where $g_{i}$ is growth rate constant for dynamic market size. Now, evolution of sales rate defined by the following differential equation as:

$$
\frac{d y_{i}(t)}{d t}=\left(a_{i}+b_{i} \frac{y_{i}(t)}{\bar{Y}_{i}(\mathrm{t})}\right)\left(u_{i}(t)+\alpha_{i} u(t)\right)\left(\bar{Y}_{i}(\mathrm{t})-y_{i}(t)\right), i=1,2, \ldots, M
$$

Under the dynamic potential market size assumption, we formulate an optimal control problem from the optimization problem Eq. (6) as:

$$
\left.\begin{array}{c}
\operatorname{Max} J=\int_{0}^{T} e^{-\gamma t}\left(\sum_{i=1}^{M}\left[\left(s_{i}-c_{i}\left(y_{i}(t)\right)\right) \dot{y}_{i}(t)-\frac{\kappa_{i}}{2} u_{i}^{2}(t)\right]-\frac{\kappa}{2} u^{2}(t)\right) d t \\
\frac{d y_{i}(t)}{d t}=\left(a_{i}+b_{i} \frac{y_{i}(t)}{\bar{Y}_{i}}\right)\left(u_{i}(t)+\alpha_{i} u(t)\right)\left(\bar{Y}_{i}-y_{i}(t)\right), y_{i}(0)=y_{i 0} \forall i=1,2, \ldots, M \\
\frac{d \bar{Y}_{i}(t)}{d t}=g_{i} \bar{Y}_{i}(t), \bar{Y}_{i}(0)=\bar{Y}_{i 0} \\
\left.\dot{B}(t)=-\left(\sum_{i=1}^{M} \frac{\kappa_{i}}{2} u_{i}^{2}(t)\right)+\psi(u(t))\right), B(0)=B_{0}, B(T) \geq 0
\end{array}\right\}
$$


Here, the Hamiltonian function is formulated as

$$
H=\left(\begin{array}{c}
\sum_{i=1}^{M}\left[\left(s_{i}-c_{i}\left(y_{i}(t)\right)+\lambda_{i}(t)\right) \dot{y}_{i}(t)-\frac{\kappa_{i}}{2} u_{i}^{2}(t)\right] \delta_{i}(t) g_{i} \bar{Y}_{i}(t)-\frac{\kappa}{2} u^{2}(t) \\
-\mu(t)\left(\sum_{i=1}^{M} \frac{\kappa_{i}}{2} u_{i}^{2}(t)+\frac{\kappa}{2} u^{2}(t)\right)
\end{array}\right)
$$

According to Eq. (23) and Maximum Principle, one can obtain the optimal promotional effort strategy as

$$
\begin{aligned}
& u_{i}^{*}(t)=\frac{1}{\kappa_{i}}\left(\frac{\left(s_{i}-c_{i}+\lambda_{i}(t)\right) \frac{\partial \dot{y}_{i}}{\partial u_{i}}}{1+\mu_{T} e^{\gamma(t-T)}}\right) \\
& \mathrm{u}^{*}(t)=\frac{1}{\kappa}\left(\frac{\left(s_{i}-c_{i}+\lambda_{i}(t)\right) \frac{\partial \dot{y}_{i}}{\partial u}}{1+\mu_{T} e^{\gamma(t-T)}}\right)
\end{aligned}
$$

For optimal control policy, the adjoint variables $\lambda_{i}(t)$ and $\delta_{i}(t)$ can be obtained as:

$$
\lambda_{i}(t)=e^{\gamma t} \int_{\mathrm{t}}^{T} e^{-\gamma t} \kappa_{i} u_{i}\left(\frac{e_{y_{i}}}{e_{u_{i}}}\right)\left(\mu_{T}+e^{\gamma(t-T)}\right) d t
$$

where, $e_{y_{i}}=\frac{\partial \dot{y}_{i}}{\partial y_{i}}$ and $e_{u_{i}}=\frac{\partial \dot{y}_{i}}{\partial u_{i}}$ are demand and promotional elasticity. And

$$
\delta_{i}(t)=e^{\left(\gamma-g_{i}\right) t} \int_{\mathrm{t}}^{T} e^{-\left(\gamma-g_{i}\right) t} \kappa_{i} u_{i}\left(\frac{\partial \dot{y}_{i}}{\partial Y_{i}} / \frac{\partial \dot{y}_{i}}{\partial u_{i}}\right)\left(1+\mu_{T}\right) d t
$$

In the case given above, the proposed optimal control model is solved by using Maximum Principle theoretically. The model is nonlinear in nature and leads to complex analytical expression. The applicability of proposed optimal control problems is illustrated through a numerical example. By using data available in discrete form, the discounted continuous optimal control problem Eq. (5) is transformed into equivalent discrete problem (Rosen, 1968). The discrete optimal control formulation of the budgetary problem can be written as follows 


$$
\operatorname{Max} J=\sum_{k=1}^{T}\left(\left(\begin{array}{c}
{\left[\sum_{i=1}^{M}\left(s_{i}-c_{i}(k)\right)\left(y_{i}(k+1)-y_{i}(k)\right)-\phi_{i}\left(u_{i}(k)\right)\right]} \\
-\psi(u(k))
\end{array}\right)\left(\frac{1}{(1+\gamma)^{k-1}}\right)\right)
$$

subjected to

$$
\begin{gathered}
y_{i}(k+1)=y_{i}(k)+\left(a_{i}+b_{i} \frac{y_{i}(k)}{\bar{Y}_{l}}\right)\left(u_{i}(k)+\alpha_{i} u(k)\right)\left(\bar{Y}_{l}-y_{i}(k)\right), i=1,2, \ldots, M \\
\sum_{k=1}^{T}\left(\sum_{i=1}^{M}\left(\phi_{i}\left(u_{i}(k)\right)\right)+\psi(u(k))\right) \leq B_{0}
\end{gathered}
$$

Due to complexity of the discretized version of the proposed optimal control problems incorporating dynamic market size, we use Lingo11 to solve the discrete formulation of both the control problems.

\section{Numerical Illustration}

In this section, numerical example incorporating dynamic market size is presented to illustrate the solution procedure and theoretical policies. Here, we consider a firm that has to find the optimal promotional effort rate policies for its consumer durable product. Firm uses promotional effort at both national and regional level of the market in segmented environment. To validate the model and find the promotional effort policy, the values of parameters, price and cost of the product which are used in the numerical solution are given in Table 1.

Table 1. The values of Parameters, price and cost of the product

\begin{tabular}{|c|c|c|c|}
\hline & S1 & S2 & S3 \\
\hline $\bar{Y}_{i}$ & 152460 & 152581 & 155586 \\
\hline$a_{i}$ & 0.001161 & 0.00138 & 0.00549 \\
\hline$b_{i}$ & 0.480575 & 0.540395 & 0.31362 \\
\hline$\alpha_{i}$ & 0.190 & 0.189 & 0.181 \\
\hline$g_{i}$ & 0.0265 & 0.0278 & 0.0276 \\
\hline$k_{i}$ & 200000 & 200000 & 200000 \\
\hline$k$ & \multicolumn{4}{|l|}{400000} & 450000 \\
\hline$\gamma$ & 440000 & 0.09 & 390000 \\
\hline$s_{i}$ & 370000 & 420000 & 11657 \\
\hline Initial Sales & 11231 & 340000 & \\
\hline
\end{tabular}

The discrete formulation of optimal control problem developed in this section with dynamic market size is solved using Lingo11. We have considered some base values for the proposed model to solve by Lingo11.The time horizon has been divided into 19 equal time periods and total promotional budget is assumed to be 500000 units. The number of market segments are three (i.e. $M=3$ ) and promotional budget has to be allocated for mass market promotion and segment specific promotion in three segments of the market. The discretized problem is solved by taking differentiated and mass promotional effort cost as a quadratic function of effort rate. The problem is coded and solved in Lingo11. The optimal value of total profit for dynamic market size is 8369287000 units with optimal mass promotional effort rate $u(t)=0.10$. The numerical solution for optimal sales, promotional efforts and sensitivity analysis are illustrated in Figures 13 respectively. 
International Journal of Mathematical, Engineering and Management Sciences

Vol. 5, No. 4, 682-696, 2020

https://doi.org/10.33889/IJMEMS.2020.5.4.055

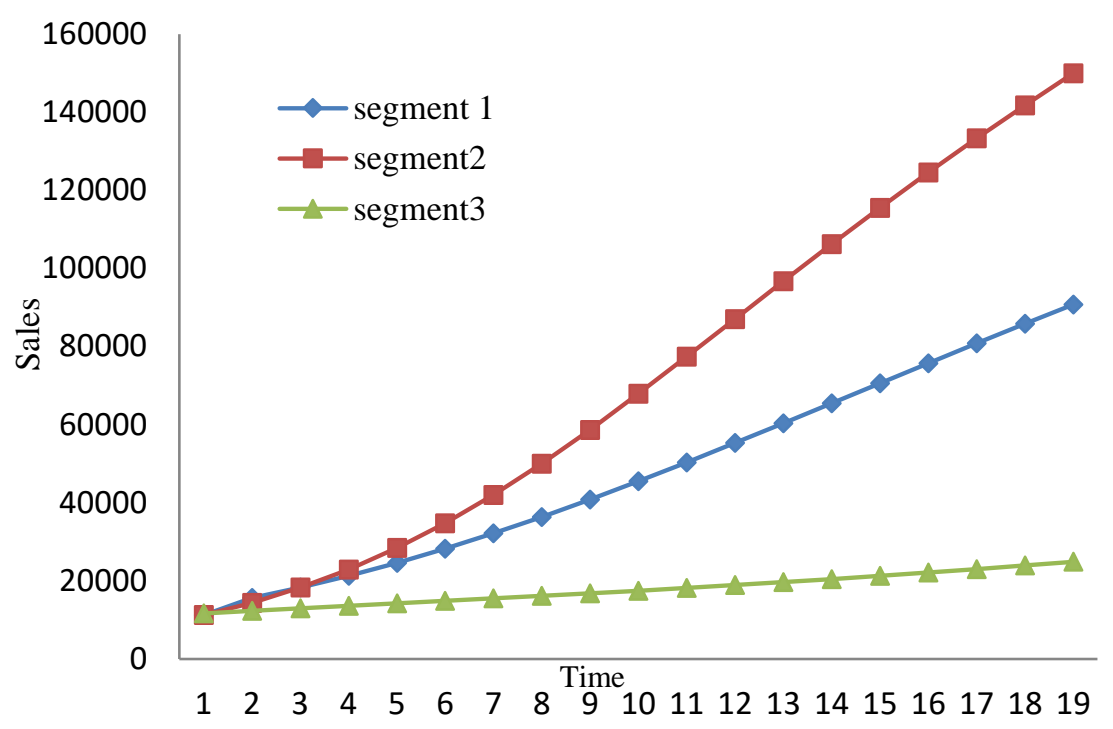

Figure 1. Optimal sales with dynamic market size

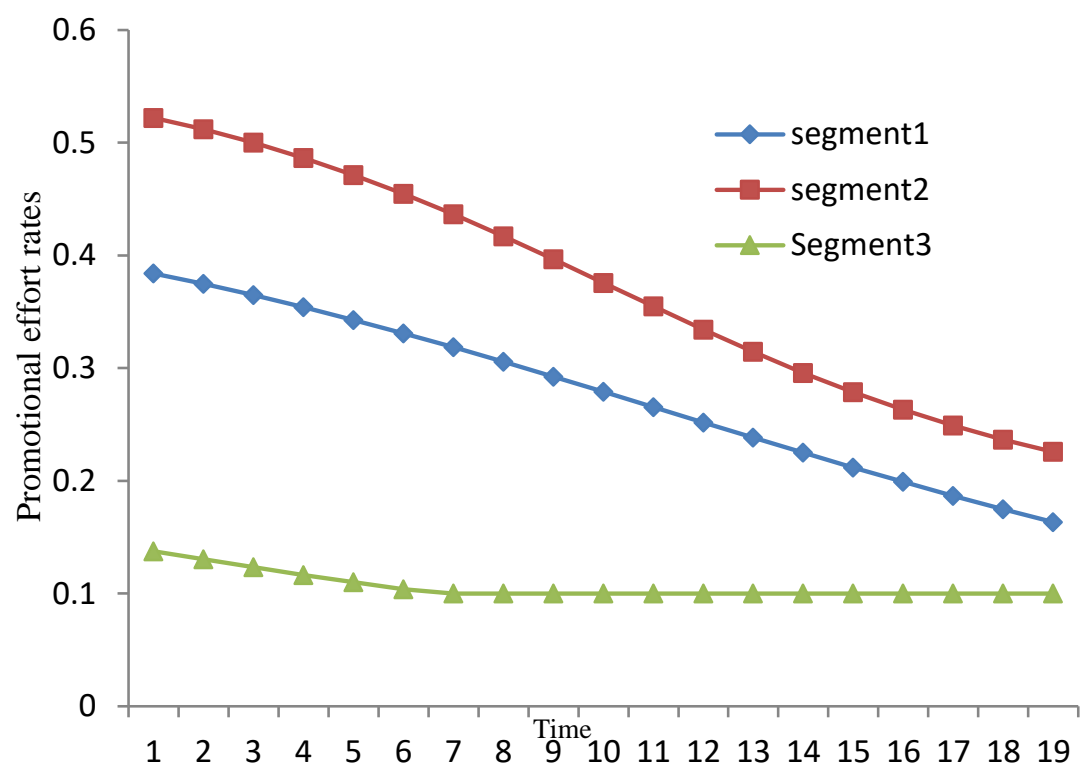

Figure 2. Optimal differentiated promotional allocation with dynamic market size 
International Journal of Mathematical, Engineering and Management Sciences

Vol. 5, No. 4, 682-696, 2020

https://doi.org/10.33889/IJMEMS.2020.5.4.055

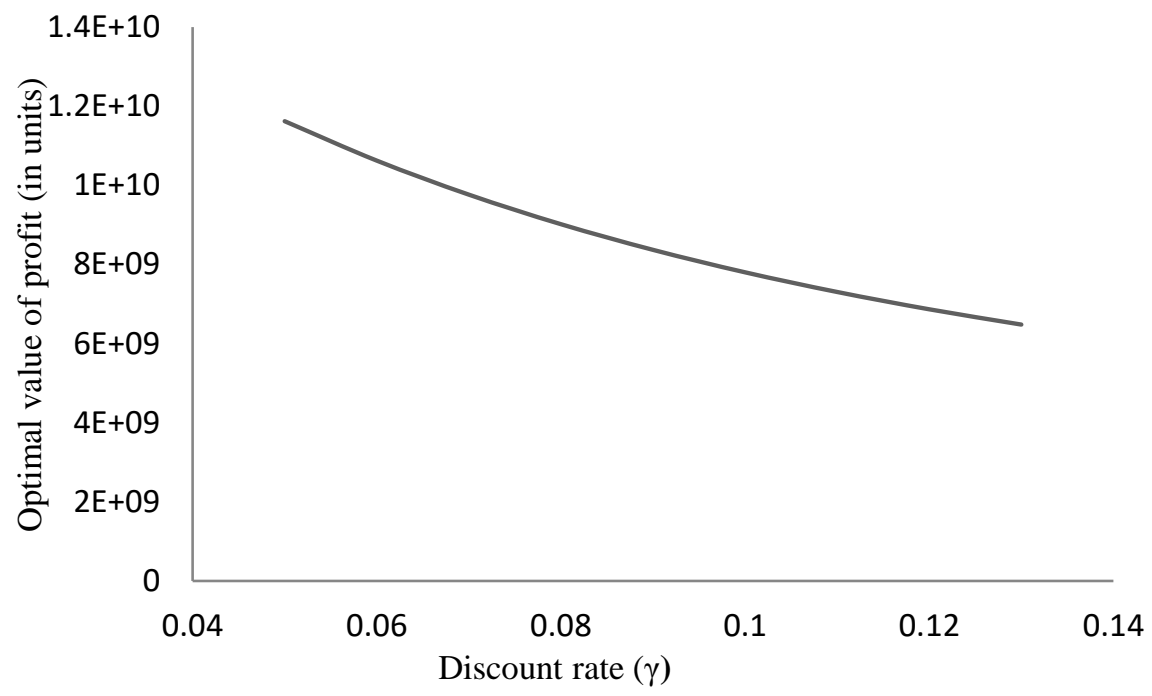

Figure 3. Optimal value of profit with different discount rates

Figure 1 depicts the graph of the optimal sales $y_{i}^{*}(t)$ from potential market for each segment. Figure 2 show the graph of optimal differentiated promotion effort rate allocation $\left(u_{i}^{*}(t)\right)$ in each segment. From figure 1 it can be concluded that sales $y_{i}^{*}(t)$ starts from initial value and then increase as time increases. Figure 2 displays that initially optimal promotional effort rate are at maximum level. It can be concluded that as untapped market potential level decreases which in turns reduces the potential adopters, the decision maker should lower the promotional effort level at the end of the planning period. Figure 3 show the optimal values of the profit for different discount rate $\gamma \in[0.04,0.14]$ incorporating dynamic market size and other parameters keep unchanged. It indicates that when the value of discount rate $\rho$ increases, the optimal value of profit decreases. Also, optimal value of total profit will decrease as value of discount rate increases. Consequently, unsaturated market level decreases which in turns reduces the sales therefore, the firm should lower the discount rate in case of saturation of market.

\section{Conclusion and Scope for Future Research}

In the era of globalization and upsurge in new technologies, a suitable decision making plan is required. As the product launch in the market, the factors like promotions, product awareness and purchase power of the consumer etc. influencing the size of the potential market. Thus it is very important for a diffusion model to allow the market size change over time. In this article, we have incorporated marketing decision features such as market segmentation, mass and differentiated promotions, market potential growth and optimal allocation of resource distribution for promotion in profit maximization model. We have developed an optimal control problem for innovationdiffusion model incorporating dynamic potential market size in segmented market where sales are evolved through the combination of mass and differentiated promotions strategies. Also, we use total budget constraint on promotional expenditure, which makes the model more realistic. After discretization the optimal control model, the proposed problems for repeat purchase and dynamic potential market size have been solved using Lingo11. Numerical examples are provided to illustrate the effectiveness of the proposed method and solution procedure. Furthermore, 
International Journal of Mathematical, Engineering and Management Sciences

Vol. 5, No. 4, 682-696, 2020

https://doi.org/10.33889/IJMEMS.2020.5.4.055

sensitivity analysis of the discount rate parameter is carried out which shows that as the value of discount rate increases, the optimal value of profit decreases. For further studies, the proposed optimal control model can be extended by incorporating the factors such as price, quality and cost along with differentiated and mass market promotional effort expenditure. It is also interesting to obtain optimal control policies for the model with two and/or more generations' product in the market.

\section{Conflict of Interest}

The authors confirm that there is no conflict of interest to declare for this publication.

\section{Acknowledgments}

The authors sincerely appreciate the editor and reviewers for their time and valuable suggestions towards the improvement in the quality of the papers.

\section{References}

Bass, F.M. (1969). A new product growth model for consumer durables. Management Science, 15(5), 215227.

Bass, F.M., Krishnan, T.V., \& Jain, D.C. (1994). Why the bass model fits without decision variables. Marketing Science, 13(3), 203-223.

Buratto, A., Grosset, L., \& Viscolani, B. (2006). Advertising a new product in segmented market. European Journal of Operational Research, 175(2), 1262-1267.

Chang, S., Zhang, Z., Wang, X., \& Dong, Y. (2020). Optimal acquisition and retention strategies in a duopoly model of competition. European Journal of Operational Research, 282(2), 677-695.

Chutani, A., \& Sethi, S.P. (2012). Optimal advertising and pricing in a dynamic durable goods supply chain. Journal of Optimization Theory and Applications, 154(2), 615-643.

De Giovanni, P. (2019). An optimal control model with defective products and goodwill damages. Annals of Operations Research, 1-12. https://doi.org/10.1007/s10479-019-03176-4.

Dockner, E., \& Jorgensen, S. (1988). Optimal advertising policies for diffusion models of new product innovation in monopolistic situations. Management Science, 34(1), 119-130.

Górajski, M., \& Machowska, D. (2017). Optimal double control problem for a PDE model of goodwill dynamics. Mathematical Methods of Operations Research, 85(3), 425-452.

Grosset, L., \& Viscolani, B. (2005). Advertising for the introduction of an age-sensitive product. Optimal Control Applications and Methods, 26(3), 157-167.

Helmes, K., Schlosser, R., \& Weber, M. (2013). Optimal advertising and pricing in a class of general newproduct adoption models. European Journal of Operational Research, 229(2), 433-443.

Horsky, D., \& Simmon, L. (1983). Advertising and diffusion of new products. Marketing Science, 2(1), 117.

Huang, J., Leng, M., \& Liang, L. (2012). Recent developments in dynamic advertising research. European Journal of Operational Research, 220(3), 591-609.

Jha, P.C., Chaudhary, K., \& Kapur, P.K. (2009). Optimal advertising control policy for a new product in segmented market. OPSEARCH, 46(2), 225-237. 
International Journal of Mathematical, Engineering and Management Sciences

Vol. 5, No. 4, 682-696, 2020

https://doi.org/10.33889/IJMEMS.2020.5.4.055

Kalish, S. (1983). Monopolist pricing with dynamic demand and product cost. Marketing Science, 2(2), $135-159$.

Kalish, S. (1985). A new product adoption model with price, advertising and uncertainty. Management Science, 31(12), 1569-1585.

Kamakura, W., \& Balasubramanium, S.K. (1988). Long-term view of the diffusion of durables a study of the role of price and adoption influence processes via tests of nested models. International Journal of Research in Marketing, 5(1), 1-13.

Kapur, P.K., Sharma, H., Tandon, A., \& Aggarwal, A.G. (2020). Studying BHIM app adoption using Bass model: an Indian perspective. International Journal of Mathematical, Engineering and Management Sciences, 5(1), 120-135.

Kumar, V., \& Sahni, R. (2016). An effort allocation model considering different budgetary constraint on fault detection process and fault correction process. Decision Science Letters, 5(1), 143-156.

Kumar, V., Kapur, P.K., Taneja, N., \& Sahni, R. (2017). On allocation of resources during testing phase incorporating flexible software reliability growth model with testing effort under dynamic environment. International Journal of Operational Research, 30(4), 523-539.

Kumar, V., Khatri, S.K., Dua, H., Sharma, M., \& Mathur, P. (2014). An assessment of testing cost with effort dependent FDP and FCP under learning effect: A Genetic Algorithm Approach. International Journal of Reliability, Quality and Safety Engineering, 21(6), 145002.

Kumar, V., Sarkar, B., Sharma, A.N., \& Mittal, M. (2019). New product launching with pricing, free replacement, rework, and warranty policies via genetic algorithmic approach. International Journal of Computational Intelligence Systems, 12(2), 519-529.

Little, J.D.C., \& Lodish, L.M. (1969). A media planning calculus. Operations Research, 17(1), 1-35.

Mesak, H.I., Bari, A., \& Ellis, T.S. (2020). Optimal dynamic marketing-mix policies for frequently purchased products and services versus consumer durable goods: A generalized analytic approach. European Journal of Operational Research, 280(2), 764-777.

Nerlove, M., \& Arrow, K.J. (1962). Optimal advertising policy under dynamic conditions. Economica, 29(114), 129-142.

Pan, X., \& Li, S. (2016). Dynamic optimal control of process-product innovation with learning by doing. European Journal of Operational Research, 248(1), 136-145.

Robinson, B., \& Lakhani, C. (1975). Dynamic price models for new product planning. Management Science, 21(10), 1113-1122.

Rosen, J.B. (1968). Numerical solution of optimal control problems. Mathematics of Decision Science, Part-2, American Mathematical Society, 37-45.

Seidmann, T.I., Sethi, S.P., \& Derzko, N. (1987). Dynamics and optimization of a distributed sales advertising model. Journal of Optimization Theory and Applications, 52(3), 443-462.

Seierstad, A., \& Sydsaeter, K. (1987). Optimal control theory with economic applications. Elsevier NorthHolland, Inc.

Sethi, S.P. \& Thompson, G.L. (2000). Optimal control theory: applications to management science and economics. Kluwer Academic Publishers, Dordrecht.

Sethi, S.P. \& Bass, F.M. (2003). Optimal pricing in a hazard rate model of demand. Optimal Control Applications and Methods, 24(4), 183-196.

Simon, H., \& Sebastian, K.H. (1987). Diffusion and advertising: the German telephone campaign. Management Science, 33(4), 451-466. 
International Journal of Mathematical, Engineering and Management Sciences

Vol. 5, No. 4, 682-696, 2020

https://doi.org/10.33889/IJMEMS.2020.5.4.055

Stummer, C., Kiesling, E., Günther, M., \& Vetschera, R. (2015). Innovation diffusion of repeat purchase products in a competitive market: an agent-based simulation approach. European Journal of Operational Research, 245(1), 157-167.

Teng, J.T., \& Thompson, G.L. (1983). Oligopoly models for optimal advertising when production costs obey a learning curve. Management Science, 29(9), 1087-1101.

Thompson, G.L., \& Teng, J.T. (1996). Optimal strategies for general price quality decision models of new products with learning production costs. European Journal of Operational Research, 93(3), 476-489.

Thompson, G.L., \& Teng, J.T. (1984). Optimal pricing and advertising policies for new product oligopoly models. Marketing Science, 3(2), 148-168. 